\title{
Theoretical studies on electron delocalisation in selenourea
}

\author{
RAJNISH MOUDGIL, PRASAD V BHARATAM, RAVNEET KAUR and \\ DAMANJIT KAUR* \\ Department of Chemistry, Guru Nanak Dev University, Amritsar 143 005, \\ India \\ e-mail: moudgil_r@rediffmail.com
}

MS received 3 October 2001; revised 1 June 2002

\begin{abstract}
A b$ initio and density functional calculations have been performed on the different possible structures of selenourea $(s u)$, urea $(u)$ and thiourea $(t u)$ to understand the extent of delocalisation in selenourea in comparison to urea and thiourea. Selenourea ( $s u-1)$ with $C_{2}$ symmetry has the minima on the potential energy surface at MP2(fu)/6-31+G* level. The $\mathrm{C}-\mathrm{N}$ rotational barrier in selenourea is $8.69 \mathrm{kcal} / \mathrm{mol}$, which is 0.29 and $0.11 \mathrm{kcal} / \mathrm{mol}$ more than that of urea and thiourea respectively at MP2(fu) $/ 6-31+\mathrm{G}^{*}$ level. $\mathrm{N}$-inversion barrier is $0.55 \mathrm{kcal} / \mathrm{mol}$ at MP2(fu)6-31+G* level. NBO analysis has been carried out to understand the nature of different interactions responsible for the electron delocalisation.
\end{abstract}

Keywords. Selenourea; electron delocalisation; C-N rotational barriers; Ninversion barriers; NBO analysis; ab initio and density functional.

\section{Introduction}

Biological studies on organoselenium compounds are of current interest ${ }^{1-9}$. Organoselenium compounds like isoselenocyanates (I), selenoformamide (II) and selenoureas (III) are important building blocks for the synthesis of biologically important selenium compounds ${ }^{2}$. For example, selenamides on reaction with 4-tolylnitrile oxide

$$
\mathrm{R}-\mathrm{N}=\mathbf{C}=\mathrm{Se}
$$

(I)<smiles>[R]NC=[Se]</smiles>

(II)<smiles>[R]NC([Se])=[Se]</smiles>

(III)

give isoselenocyanates, which on further reaction with amides give selenourea ${ }^{7}$. Selenourea on reaction with $\beta$-ketoesters yields selenouracil ${ }^{8}$. Many cyclic selenoureas have found application in carbohydrate research ${ }^{9}$. Electron delocalisation in these systems plays an important role in their conformational stability and reactivity. For example, molecular flexibility in acylselenoureas has been shown to be controlled by the restricted rotations in the selenourido group ${ }^{10}$. It is important to study the electron delocalisations in selenourea in order to estimate its molecular rigidity.

\footnotetext{
*For correspondence
} 
Theoretical studies showed that the electron delocalisation in selenoformamide is stronger than that in thioformamide and formamide ${ }^{11}$. Similarly electron delocalisation in selenoisocyanates is stronger than that in thioisocyanates and isocyanates ${ }^{12}$. These facts indicate that the electron delocalisation in selenourea should be larger than that in thiourea and urea. However, since the electronegativity of Se (2.4) is less than that of $S$ $(2 \cdot 5)$ and $\mathrm{O}(3 \cdot 5)$, according to the resonance model (scheme 1), electron delocalisation in selenourea should be less than that of urea and thiourea. Wiberg et al ${ }^{13 a}$ studied the resonance in amides and thioamides by performing ab initio calculations, using density difference maps and concluded that the charge polarization in $\mathrm{C}-\mathrm{S}$ bond is much weaker and hence the contribution from resonance structure $\mathbf{2}$ is greatly reduced relative to that in amides (scheme 1). Glendening and $\mathrm{Hrabal}^{14}$ studied the problem using natural resonance theory and concluded that the weight of the dipolar form increases from formamide to telluroformamide and showed that polarisability of the $\mathrm{C}-\mathrm{X}$ bond rather than electronegativity of $\mathrm{X}$ plays important role in allowing the chalcogen to accommodate more charge density. On the basis of integrated Fermi correlation, Ladig and Camaron ${ }^{15}$ showed that the thioamides should be viewed as special cases of amines. Lauvergnat and Hiberty ${ }^{16}$ employing valence bond theory showed that resonance stabilization does not wholly account for the $\mathrm{C}=\mathrm{N}$ bond rotational barriers and the preference of the nitrogen lone pair to stay perpendicular to the molecular plane also should be considered. Wiberg and Rush ${ }^{14 a}$ as well as Lauvergnat and Hiberty ${ }^{16}$ pointed out that the greater charge transfer from $\mathrm{N}$ to $\mathrm{S}$ in thioamides as compared that from $\mathrm{N}$ to $\mathrm{O}$ in amides is responsible for the greater electron delocalisation in thioamides. In this paper we report $a b$ initio MO and density functional study on the electron delocalisation in selenourea $(s u)$. Second order electronic interactions in selenourea have been quantitatively estimated using the natural bond orbital method (NBO) and compared with that in urea $(u)$ and thiourea $(t u)$.

\section{Methods of calculation}

$A b$ initio $^{17}$ and density functional calculations (DFT) ${ }^{18}$ have been performed using the Windows version of the GAUSSIAN94 program ${ }^{19}$. Optimizations have been carried out on different possible structures of urea, thiourea and selenourea including their rotational transition states and inversion transition states etc. at $\mathrm{HF} / 6-31+\mathrm{G}^{*}$ basis set. Since these molecules possess several lone pairs of electrons, diffuse functions have been included in the basis set ${ }^{17}$. To study the effect of electron correlation on the geometry, full optimizations have been carried out at MP2(fu)/6-31+G*20 and B3LYP/6-31+G*21 levels. Frequencies have been computed for all optimized structures to characterize each stationary point as a minimum or a transition state and to determine ZPE values. ZPE values have been scaled by the factor of $0.9153^{22}$. NBO analysis has been carried out to

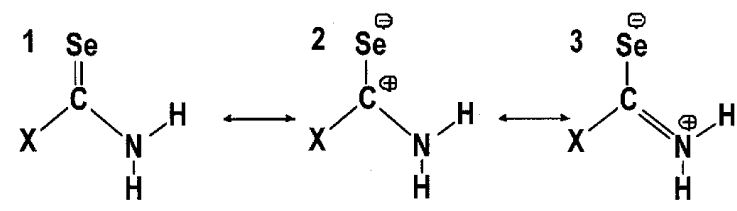

Scheme 1. 
understand various second-order interactions. Atomic charges have been estimated using $\mathrm{NPA}^{23}$ method with MP2 densities at MP2(fu)/6-31+G* level.

\section{Results and discussion}

\subsection{Geometric structures}

The possible conformations of selenourea are shown in figure 1. su-2 having $\mathrm{C}_{2 v}$ symmetry has been found to be the minimum energy structure after complete optimization at $\mathrm{HF} / 6-31+\mathrm{G}^{*}$. However at electron correlated level MP2/6-31+G* $s u-2$ showed two negative frequencies which correspond to inversion at two nitrogen atoms. $s u-2$ having a planar $\mathrm{C}_{2 v}$ arrangement showed one negative frequency at other theoretical levels like MP2(fu)/6-31+G*, B3LYP/6-31+G* and B3PW91/6-31+G*. su-1 with $C_{2}$ symmetry has been found to be the minimum after complete optimization at MP2(fu)/6$31+\mathrm{G}^{*}$ and B3LYP/6-31+G* levels. The sum of angles around nitrogen $350 \cdot 1^{\circ}$ and $354.5^{\circ}$ at MP2(fu)/6-31+G* and B3LYP/6-31+G* levels respectively, indicate the pyramidalization at both nitrogens in $s u-1$. These calculations were carried out at other theoretical levels to confirm these results (table 1). It is amply clear that $s u-1$ with $C_{2}$ symmetry is the most preferable structure. su-3 with $C_{s}$ symmetry has also been found on

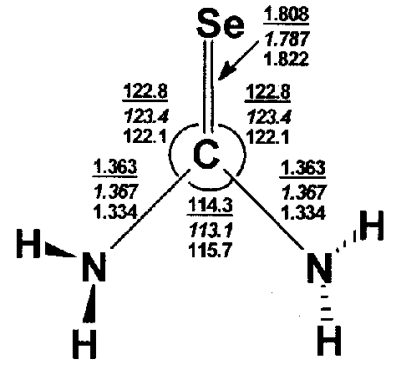

su-1, $c_{2}$

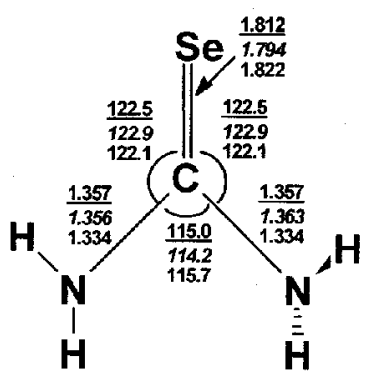

su- $4, c_{1}$

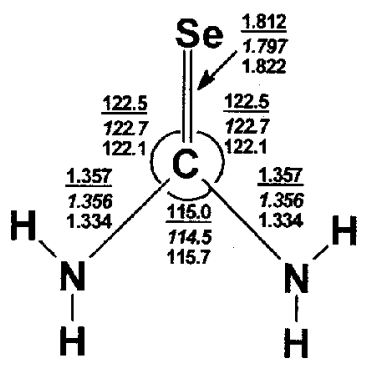

su-2, $C_{2 v}$

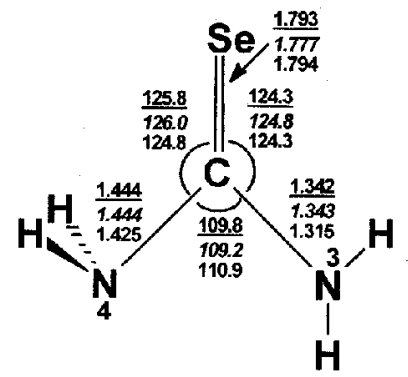

su-5, $C_{s}$

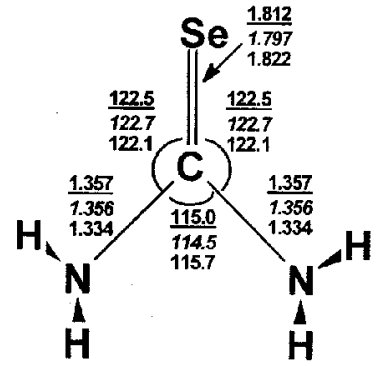

su-3, $C_{s}$

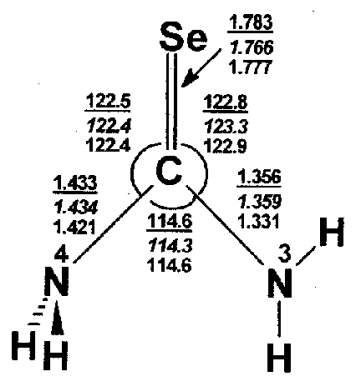

su-6, $C_{s}$

Figure 1. Different structures of selenourea along with their important geometric parameters at three levels, viz. HF/6-31+G*, MP2(fu)/6-31+G* and B3LYP/6-31+G*. Distances are in ångstroms and angles are in degrees. 
Table 1. Relative energies (ZPE corrected, in $\mathrm{kcal} / \mathrm{mol}$ ) of various structures of urea, thiourea and selenourea obtained using different theoretical methods.

\begin{tabular}{|c|c|c|c|c|c|c|}
\hline Structure & Symmetry & $\begin{array}{l}\mathrm{HF} / 6- \\
31+\mathrm{G}^{*}\end{array}$ & $\begin{array}{l}\text { MP2/6- } \\
31+G^{*}\end{array}$ & $\begin{array}{c}\mathrm{MP} 2(\mathrm{fu}) / 6- \\
31+\mathrm{G}^{*}\end{array}$ & $\begin{array}{c}\text { B3LYP/6- } \\
\text { 31+G* }\end{array}$ & $\begin{array}{c}\text { B3PW91/6- } \\
31+\mathrm{G}^{*}\end{array}$ \\
\hline$u-1$ & $C_{2}$ & 0.00 & 0.00 & 0.00 & 0.00 & 0.00 \\
\hline$u-2$ & $C_{2 v}$ & $1 \cdot 18$ & $2 \cdot 43$ & $2 \cdot 31$ & 1.27 & 1.26 \\
\hline$u-3$ & $C_{\mathrm{s}}$ & 1.05 & $1 \cdot 35$ & $1 \cdot 33$ & 0.97 & 0.99 \\
\hline$u-4$ & $C_{1}$ & 0.90 & $1 \cdot 58$ & $1 \cdot 52$ & 0.87 & 0.93 \\
\hline$u-5$ & $C_{s}$ & 8.93 & $8 \cdot 39$ & 8.40 & $8 \cdot 28$ & $8 \cdot 32$ \\
\hline$u-6$ & $C_{s}$ & $15 \cdot 54$ & $15 \cdot 11$ & $15 \cdot 12$ & $14 \cdot 60$ & $14 \cdot 73$ \\
\hline$t u-1$ & $C_{2}$ & 0.00 & 0.00 & 0.00 & 0.00 & 0.00 \\
\hline$t u-2$ & $C_{2 v}$ & 0.02 & $1 \cdot 36$ & $1 \cdot 22$ & 0.45 & 0.45 \\
\hline$t u-3$ & $C_{s}$ & - & 1.06 & 1.01 & - & - \\
\hline$t u-4$ & $C_{1}$ & - & 1.02 & 0.94 & $0 \cdot 41$ & 0.42 \\
\hline$t u-5$ & $C_{s}$ & $10 \cdot 56$ & $8 \cdot 57$ & $8 \cdot 58$ & $9 \cdot 07$ & $9 \cdot 12$ \\
\hline$t u-6$ & $C_{s}$ & $18 \cdot 85$ & $16 \cdot 04$ & $16 \cdot 04$ & $16 \cdot 57$ & $16 \cdot 81$ \\
\hline su-1 & $C_{2}$ & 0.00 & $0 \cdot 00$ & 0.00 & 0.00 & 0.00 \\
\hline$s u-2$ & $C_{2 v}$ & 0.00 & 0.73 & 0.59 & $0 \cdot 11$ & $0 \cdot 11$ \\
\hline$s u-3$ & $C_{s}$ & - & $0 \cdot 73$ & 0.60 & - & - \\
\hline su-4 & $C_{1}$ & - & $0 \cdot 64$ & 0.55 & - & - \\
\hline$s u-5$ & $C_{s}$ & $11 \cdot 51$ & $8 \cdot 68$ & 8.69 & $9 \cdot 25$ & $9 \cdot 28$ \\
\hline$s u-6$ & $C_{s}$ & $20 \cdot 43$ & $16 \cdot 77$ & $16 \cdot 79$ & $17 \cdot 11$ & $17 \cdot 33$ \\
\hline
\end{tabular}

the potential energy surface, which has pyramidal arrangement of $\mathrm{NH}_{2}$ groups towards the same side of the molecular plane. $s u-3$ showed one negative frequency with almost planar arrangement. $s u-1$ is only $0.60 \mathrm{kcal} / \mathrm{mol}$ lower in energy than $s u-3$ at MP2(fu)/ $6-31+\mathrm{G}^{*}$. The $\mathrm{Se}-\mathrm{C}$ bond lengths in $\mathrm{su}-1$ at $\mathrm{HF} / 6-31+\mathrm{G}^{*}, \mathrm{MP} 2(\mathrm{fu}) / 6-31+\mathrm{G}^{*}$ and B3LYP/ $6-31+\mathrm{G}^{*}$ are $1.822,1.787$ and $1.808 \AA$ respectively (table 2 ) which is comparable to experimental bond lengths $1.79-1.84 \AA$ reported using X-ray crystal structure of cyclic selenoureas ${ }^{10}$.

The Se-C bond length in su- 1 is slightly longer than the $\mathrm{Se}-\mathrm{C}$ double bond lengths in $\mathrm{H}_{2} \mathrm{C}=\mathrm{Se}$ which are $1.722,1.745$ and $1.744 \AA$ at $\mathrm{HF} / 6-31+\mathrm{G}^{*}, \mathrm{MP} 2(\mathrm{fu}) / 6-31+\mathrm{G}^{*}$ and B3LYP/6-31+G* respectively. This elongation of the $\mathrm{Se}-\mathrm{C}$ bond in $s u-1$ in comparison to that in selenoformaldehyde can be attributed to delocalisation of lone pairs on the nitrogens. The $\mathrm{C}-\mathrm{N}$ bond lengths in $s u-1$ (1.334, 1.367 and $1.363 \AA$ at $\mathrm{HF} / 6-31+\mathrm{G}^{*}$, $\mathrm{MP} 2(\mathrm{fu}) / 6-31+\mathrm{G}^{*}$ and $\mathrm{B} 3 \mathrm{LYP} / 6-31+\mathrm{G}^{*}$ levels respectively) are smaller than the $\mathrm{C}-\mathrm{N}$ single bond lengths in $\mathrm{H}_{3} \mathrm{C}-\mathrm{NH}_{2}\left(1.454,1.465\right.$ and $1.466 \AA$ at $\mathrm{HF} / 6-31+\mathrm{G}^{*}, \mathrm{MP} 2(\mathrm{fu}) / 6-$ $31+\mathrm{G}^{*}, \mathrm{~B} 3 \mathrm{LYP} / 6-31+\mathrm{G}^{*}$ levels respectively) and longer than the double bond lengths in $\mathrm{H}_{2} \mathrm{C}=\mathrm{NH} \quad\left(1.252,1.283,1.273 \AA\right.$ at $\mathrm{HF} / 6-31+\mathrm{G}^{*}, \mathrm{MP} 2(\mathrm{fu}) / 6-31+\mathrm{G}^{*}, \mathrm{~B} 3 \mathrm{LYP} / 6-31+\mathrm{G}^{*}$ respectively). This bond shortening in $s u-1$ clearly supports the delocalisation of the lone pair on nitrogen.

The $\mathrm{C}-\mathrm{N}$ bond lengths in the three systems are in the order $u-1(1.388 \AA)>t u-1$ $(1.374 \AA)>s u-1 \quad(1.367 \AA)$ at MP2(fu)6-31+G* level (table 2). Similarly the X-C bond lengths are in the order $u-1(1.229 \AA)<t u-1(1.650 \AA)<s u-1(1.787 \AA)$ at the MP2(fu)/6$31+\mathrm{G}^{*}$ level. The pyramidalisation around $\mathrm{N}$ is in the order $u-1>t u-1>s u-1$ because the sum of angles around nitrogen is in the order $u-1 \quad\left(343 \cdot 2^{\circ}\right)<t u-1>\left(347 \cdot 1^{\circ}\right)<s u-1$ $\left(350 \cdot 1^{\circ}\right)$. The contraction of the $\mathrm{C}-\mathrm{N}$ bond lengths and elongation of the $\mathrm{X}-\mathrm{C}$ bond lengths (relative to the expected $\mathrm{X}-\mathrm{C}$ bond distance) clearly indicate an increase in the $\mathrm{X}-\mathrm{C}-\mathrm{N}$ electron delocalisation as we move down the group from $\mathrm{O}$ to $\mathrm{Se}$. 
Table 2. Important geometric parameters of urea $(u-1)$, thiourea $(t u-1)$ and selenourea $(s u-1)$ at different levels.

Distances are in ångstroms and angles are in degrees

\begin{tabular}{|c|c|c|c|c|}
\hline Level & $\mathrm{X}-\mathrm{C}$ & $\mathrm{C}-\mathrm{N}$ & $\mathrm{X}-\mathrm{C}-\mathrm{N}$ & $\varphi$ \\
\hline \multicolumn{5}{|l|}{ Urea } \\
\hline $\mathrm{HF} / 6-31+\mathrm{G}^{*}$ & $1 \cdot 200$ & $1 \cdot 372$ & $122 \cdot 8$ & $346 \cdot 6$ \\
\hline MP2/6-31+G* & $1 \cdot 230$ & $1 \cdot 389$ & $123 \cdot 2$ & $342 \cdot 9$ \\
\hline MP2(fu)/6-31+G* & 1.229 & $1 \cdot 388$ & $123 \cdot 2$ & $343 \cdot 2$ \\
\hline B3LYP/6-31+G* & $1 \cdot 224$ & $1 \cdot 388$ & $122 \cdot 9$ & 345.9 \\
\hline B3PW91/6-31+G* & $1 \cdot 222$ & $1 \cdot 384$ & $122 \cdot 9$ & $345 \cdot 8$ \\
\hline \multicolumn{5}{|l|}{ Thiourea } \\
\hline $\mathrm{HF} / 6-31+\mathrm{G}^{*}$ & $1 \cdot 680$ & $1 \cdot 340$ & $122 \cdot 1$ & $358 \cdot 0$ \\
\hline $\mathrm{MP} 2 / 6-31+\mathrm{G}^{*}$ & $1 \cdot 652$ & $1 \cdot 376$ & $123 \cdot 5$ & $346 \cdot 7$ \\
\hline $\mathrm{MP} 2(\mathrm{fu}) / 6-31+\mathrm{G}^{*}$ & 1.650 & $1 \cdot 374$ & $123 \cdot 5$ & $347 \cdot 1$ \\
\hline B3LYP/6-31+G* & 1.673 & $1 \cdot 369$ & $122 \cdot 8$ & $351 \cdot 2$ \\
\hline B3PW91/6-31+G* & 1.667 & $1 \cdot 365$ & $122 \cdot 7$ & $351 \cdot 2$ \\
\hline \multicolumn{5}{|l|}{ Selenourea } \\
\hline $\mathrm{HF} / 6-31+\mathrm{G}^{*}$ & $1 \cdot 822$ & $1 \cdot 334$ & $122 \cdot 1$ & $360 \cdot 0$ \\
\hline MP2/6-31+G* & 1.792 & $1 \cdot 369$ & $123 \cdot 5$ & $349 \cdot 4$ \\
\hline $\mathrm{MP} 2(\mathrm{fu}) / 6-31+\mathrm{G}^{*}$ & 1.787 & $1 \cdot 367$ & $124 \cdot 4$ & $350 \cdot 1$ \\
\hline B3LYP/6-31+G* & $1 \cdot 808$ & $1 \cdot 363$ & $122 \cdot 8$ & $354 \cdot 5$ \\
\hline B3PW91/6-31+G* & 1.799 & $1 \cdot 359$ & $122 \cdot 8$ & $354 \cdot 4$ \\
\hline
\end{tabular}

\subsection{Rotational and inversion processes}

Two rotational transition states su-5 and $s u-6$ with $C_{s}$ symmetry have been found on the potential energy surface. The difference between them is that $s u-5$ has syn arrangement of $\mathrm{Se}-\mathrm{C}-\mathrm{NH}_{2}$ unit and su-6 has anti arrangement of $\mathrm{Se}-\mathrm{C}-\mathrm{NH}_{2}$ unit. Structure su-6 is higher in energy $(8 \cdot 1 \mathrm{kcal} / \mathrm{mol}$ at MP2(fu)6-31+G*) than su-5 at all levels (table 2) which can be attributed to repulsion between lone pairs on Se and $\mathrm{N}$. The $\mathrm{C}-\mathrm{N}$ rotational barrier has been calculated to be the difference between $s u-1$ and $s u-5$. The rotational barrier at $\mathrm{HF} / 6-31+\mathrm{G}^{*}$ is $11.51 \mathrm{kcal} / \mathrm{mol}$ which is reduced to 8.68 (MP2/6-31+G*), 8.69 (MP2(fu)/6-31+G*) and $9 \cdot 25 \mathrm{kcal} / \mathrm{mol}$ (B3LYP/6-31+G*) after including the electron correlation. This value is much higher than $\mathrm{C}-\mathrm{N}$ single bond rotational barrier in $\mathrm{H}_{3} \mathrm{C}-$ $\mathrm{NH}_{2}$, indicating strong restriction in the $\mathrm{C}-\mathrm{N}$ rotational process. This higher rotational barrier can be attributed to the partial double bond character between $\mathrm{C}$ and N. During rotation the $\mathrm{C}-\mathrm{N}$ bond elongation $\left(0.077 \AA\right.$ at $\left.\mathrm{MP} 2(\mathrm{fu}) / 6-31+\mathrm{G}^{*}\right)$ and $\mathrm{Se}-\mathrm{C}$ bond shortening $\left(0 \cdot 010 \AA\right.$ at $\left.\mathrm{MP} 2(\mathrm{fu}) / 6-31+\mathrm{G}^{*}\right)$ further support the electron delocalisation in selenourea in accordance with resonance model. Table 2 shows that $\mathrm{C}-\mathrm{N}$ rotational barrier in $s u-1$ is larger than that $u-1$ and $t u-1$ at all levels of calculations. The $\mathrm{C}-\mathrm{N}$ rotational barriers increase in the order $u-1(8.40)<t u-1(8.58)<s u-1(8.69 \mathrm{kcal} / \mathrm{mol})$ at MP2(fu)/6-31+G* level. The elongation of the $\mathrm{C}-\mathrm{N}$ bond length and contraction of the $\mathrm{X}-\mathrm{C}$ bond length during the rotation also follow similar trends, which clearly indicate an increase in the $\mathrm{X}-\mathrm{C}-\mathrm{N}$ electron delocalisation as we move down a group.

Calculations have also been carried out for the N-inversion transition state $s u-4$ with $C_{1}$ symmetry by forcing one of the nitrogens to be planar and allowing the other to optimize. The N-inversion barrier has been calculated to be the difference of $s u-1$ and $s u-4$. The inversion barrier is $0.64 \mathrm{kcal} / \mathrm{mol}$ (at MP2/6-31+G*) and $0.55 \mathrm{kcal} / \mathrm{mol}$ (at MP2(fu)/6- 
$\left.31+\mathrm{G}^{*}\right)$. The $\mathrm{N}$-inversion barrier in $s u-1$ is lower than $u-1$ and $t u-1$ at all levels of theoretical calculations. The N-inversion barrier is in the order of $u-1(1.52 \mathrm{kcal} /$ $\mathrm{mol})>t u-1 \quad(0.94 \mathrm{kcal} / \mathrm{mol})>s u-1 \quad(0.55 \mathrm{kcal} / \mathrm{mol}) \quad$ which clearly indicate increasing delocalisation in the order $u-1<t u-1<s u-1$.

\subsection{NBO analysis}

NBO analysis (table 3) shows that $x_{\mathrm{N}} \rightarrow \pi^{*}{ }_{\mathrm{C}-\mathrm{X}}$ delocalisations increase in the order $\mathrm{O}<\mathrm{S}<\mathrm{Se}$. The second-order energy $E^{(2)}$ associated with this delocalisation in $u-1, t u-1$ and $s u-1$ are $56.75,73.52$ and $83.60 \mathrm{kcal} / \mathrm{mol}$ respectively at MP2(fu)/6-31+G* level. This trend in delocalisation is further confirmed by the decrease in the electron density of the lone pair on $\mathrm{N}$ in the order $u-1(1.892)>t u-1(1.824)>s u-1$ (1.807) and increase in electron densities of $\pi^{*}{ }_{\mathrm{X}-\mathrm{C}}$ orbitals in the order $u-1(0.258)<t u-1(0.346)<s u-1(0.378)$. The transition state structures $u-5, t u-5$ and $s u-5$ are characterized by $n_{\mathrm{N}} \rightarrow \sigma^{*}{ }_{\mathrm{C}-x}$ and $n_{\mathrm{N}} \rightarrow \sigma^{*}{ }_{\mathrm{C}-\mathrm{N}}$ negative hyperconjugative interactions which decrease with decrease in the electronegativity of $\mathrm{X}$ which is responsible for the increase in the $\mathrm{C}-\mathrm{N}$ rotational barrier in the order $\mathrm{O}<\mathrm{S}<\mathrm{Se}$. The atomic charges calculated using the NPA method (table 4) within $\mathrm{NBO}$ analysis indicate that $\mathrm{C}-\mathrm{X}$ bond polarizations decrease in the order, urea $(1.742 e)>$ thiourea $(0.651 e)>$ selenourea $(0.597 e)$ and hence increase in the delocalisations on moving from $\mathrm{O}$ to Se.

The above analysis on urea $(u)$, thiourea $(t u)$ and selenourea $(s u)$ clearly indicates that the electron delocalisation increase in the order $\mathrm{O}<\mathrm{S}<\mathrm{Se}$. Since the observed delocalisation order is in apparent contradiction to the resonance model proposed by Pauling because according to the resonance model, electron delocalisation should increase with increase in electronegativity of the element. NBO analysis indicates that orbital interactions rather than electronegativities play an important role in deciding electron delocalisation.

Table 3. NBO analysis of urea $(u)$, thiourea $(t u)$ and selenourea $(s u)$ at MP2(fu)/ $6-31+\mathrm{G}^{*}$ level.

\begin{tabular}{|c|c|c|c|c|c|}
\hline \multirow[b]{2}{*}{ Compound } & \multirow[b]{2}{*}{ Interaction } & \multirow{2}{*}{$\begin{array}{c}\text { Occupancy } \\
\rho_{n(\mathrm{~N})}\end{array}$} & \multicolumn{3}{|c|}{ Second-order interaction } \\
\hline & & & $E^{(2) \mathrm{a}}$ & $E_{(e j)}-E_{(i)}^{\mathrm{b}}$ & $F_{(i, j)}{ }^{\mathrm{b}}$ \\
\hline$u-1$ & $n_{\mathrm{N}}-\pi^{*}{ }_{\mathrm{O}-\mathrm{C} 2}$ & $1 \cdot 892$ & $56 \cdot 75$ & $0 \cdot 65$ & $1 \cdot 177$ \\
\hline \multirow[t]{3}{*}{$u-5$} & $n_{\mathrm{N} 3}-\pi^{*}{ }_{\mathrm{O}-\mathrm{C} 2}$ & 1.790 & 94.91 & $0 \cdot 58$ & $0 \cdot 168$ \\
\hline & $n_{\mathrm{N} 4}-\sigma^{*}{ }_{\mathrm{O}-\mathrm{C} 2}$ & 1.968 & $15 \cdot 14$ & 1.41 & $0 \cdot 131$ \\
\hline & $n_{\mathrm{N} 4}-\sigma^{*}{ }_{\mathrm{C} 2-\mathrm{C} 4}$ & - & $4 \cdot 35$ & $1 \cdot 26$ & $0 \cdot 067$ \\
\hline$t u-1$ & $n_{\mathrm{N}}-\pi^{*}{ }_{\mathrm{S}-\mathrm{C} 2}$ & $1 \cdot 824$ & $73 \cdot 52$ & 0.52 & $0 \cdot 182$ \\
\hline \multirow[t]{3}{*}{$t u-5$} & $n_{\mathrm{N} 3}-\pi^{*}{ }_{\mathrm{S}-\mathrm{C} 2}$ & 1.720 & $122 \cdot 09$ & 0.46 & $0 \cdot 213$ \\
\hline & $n_{\mathrm{N} 4}-\sigma^{*}{ }_{\mathrm{S}-\mathrm{C} 2}$ & 1.965 & $11 \cdot 70$ & $1 \cdot 06$ & $0 \cdot 100$ \\
\hline & $n_{\mathrm{N} 4}-\sigma^{*}{ }_{\mathrm{C} 2-\mathrm{N} 3}$ & - & 6.63 & $1 \cdot 25$ & 0.082 \\
\hline$s u-1$ & $n_{\mathrm{N}}-\pi^{*} \mathrm{Se}-\mathrm{C} 2$ & $1 \cdot 807$ & 83.60 & 0.49 & $0 \cdot 189$ \\
\hline su-2 & $n_{\mathrm{N}}-\pi^{*} \mathrm{Se}-\mathrm{C} 2$ & $1 \cdot 782$ & $104 \cdot 52$ & $0 \cdot 45$ & $0 \cdot 203$ \\
\hline \multirow[t]{3}{*}{$s u-5$} & $n_{\mathrm{N} 3}-\pi^{*} \mathrm{Se}-\mathrm{C} 2$ & $1 \cdot 701$ & 132.79 & $0 \cdot 44$ & $0 \cdot 216$ \\
\hline & $n_{\mathrm{N} 4}-\sigma^{*} \mathrm{Se}-\mathrm{C} 2$ & 1.963 & 11.51 & $0 \cdot 94$ & 0.093 \\
\hline & $n_{\mathrm{N} 4}-\sigma^{*}{ }_{\mathrm{C} 2-\mathrm{N} 3}$ & - & $7 \cdot 03$ & $1 \cdot 25$ & 0.084 \\
\hline \multirow[t]{3}{*}{ su-6 } & $n_{\mathrm{N} 3}-\pi^{*}{ }_{\mathrm{Se}-\mathrm{C} 2}$ & 1.742 & $113 \cdot 28$ & $0 \cdot 46$ & $0 \cdot 204$ \\
\hline & $n_{\mathrm{N} 4}-\sigma^{*} \mathrm{Se}-\mathrm{C} 2$ & 1.964 & $2 \cdot 33$ & 0.92 & 0.041 \\
\hline & $n_{\mathrm{N} 4}-\sigma^{*} \mathrm{C} 2-\mathrm{N} 4$ & & $14 \cdot 10$ & $1 \cdot 19$ & $0 \cdot 116$ \\
\hline
\end{tabular}

${ }^{\mathrm{a}}$ In $\mathrm{kcal} / \mathrm{mol} ;{ }^{\mathrm{b}}$ in au 
Table 4. Atomic charges and group charges in urea, thiourea and selenourea calculated using NBO method.

\begin{tabular}{|c|c|c|c|c|}
\hline Structure & $\mathrm{X}$ & $\mathrm{C}$ & $\mathrm{N}^{3} \mathrm{H}_{2}$ & $\mathrm{~N}^{4} \mathrm{H}_{2}$ \\
\hline$u-1$ & $-0 \cdot 753$ & $0 \cdot 971$ & $-0 \cdot 109$ & $-0 \cdot 109$ \\
\hline$u-2$ & $-0 \cdot 777$ & 0.972 & -0.098 & -0.098 \\
\hline$u-3$ & -0.763 & 0.969 & $-0 \cdot 103$ & $-0 \cdot 103$ \\
\hline$u-4$ & $-0 \cdot 767$ & 0.971 & -0.093 & $-0 \cdot 111$ \\
\hline$u-5$ & -0.739 & $0 \cdot 960$ & $-0 \cdot 054$ & $-0 \cdot 167$ \\
\hline$u-6$ & -0.699 & 0.959 & -0.093 & $-0 \cdot 167$ \\
\hline tu- 1 & $-0 \cdot 267$ & $0 \cdot 384$ & -0.059 & -0.059 \\
\hline$t u-2$ & $-0 \cdot 311$ & 0.398 & -0.043 & -0.043 \\
\hline$t u-3$ & $-0 \cdot 294$ & $0 \cdot 392$ & -0.049 & -0.049 \\
\hline$t u-4$ & $-0 \cdot 295$ & 0.393 & -0.040 & -0.058 \\
\hline$t u-5$ & $-0 \cdot 231$ & $0 \cdot 356$ & $-0 \cdot 010$ & -0.135 \\
\hline$t u-6$ & $-0 \cdot 158$ & $0 \cdot 342$ & $-0 \cdot 037$ & $-0 \cdot 146$ \\
\hline$s u-1$ & $-0 \cdot 247$ & $0 \cdot 350$ & $-0 \cdot 052$ & -0.052 \\
\hline$s u-2$ & $-0 \cdot 284$ & 0.362 & -0.039 & -0.039 \\
\hline$s u-3$ & $-0 \cdot 284$ & $0 \cdot 362$ & -0.039 & -0.039 \\
\hline su-4 & $-0 \cdot 276$ & $0 \cdot 359$ & -0.037 & -0.047 \\
\hline su-5 & $-0 \cdot 198$ & $0 \cdot 317$ & -0.017 & $-0 \cdot 136$ \\
\hline su-6 & $-0 \cdot 119$ & $0 \cdot 300$ & -0.001 & $-0 \cdot 150$ \\
\hline
\end{tabular}

Wiberg et al $^{14}$ have extensively studied the electron delocalisation in formamide and thioformamide. Using density maps and polarisation across $\mathrm{C}-\mathrm{X}$ bonds they have suggested that the larger $\mathrm{C}-\mathrm{N}$ barrier in thioformamide relative to formamide can be attributed to larger polarisability of the $\mathrm{C}-\mathrm{S}$ bond relative to the $\mathrm{C}-\mathrm{O}$ bond. The valence bond study by Lauvergnant and Hiberty ${ }^{16}$ also supported the above arguments. Hence, it may be concluded that the smaller charge separation in the $\mathrm{C}-\mathrm{Se}$ bond i.e. stronger polarisability of the $\mathrm{C}-\mathrm{Se}$ bond relative to $\mathrm{C}-\mathrm{S}$ and $\mathrm{C}-\mathrm{O}$ bonds is responsible for the stronger electron delocalisation in $s u-1$.

\section{Conclusions}

$A b$ initio and density functional calculations clearly indicate that electron delocalisation in $s u-1$ is due to $n_{\mathrm{N}} \rightarrow \pi^{*}{ }_{\mathrm{C}-\mathrm{X}}$ delocalisation as expected from the resonance model. The electron delocalisation in $s u-1$ is larger than that in urea and thiourea. The increase in the $\mathrm{C}-\mathrm{N}$ rotational barrier, increase in the $\mathrm{Se}-\mathrm{X}$ bond length, decrease in the $\mathrm{C}-\mathrm{N}$ bond length and decrease in the $\mathrm{N}$-inversion barrier can be attributed to the increase in the electron delocalisation in the order of $u-1<t u-1<s u-1$, which is also evidenced by the order of the second-order energy $E^{(2)}$ associated with $n_{\mathrm{N}} \rightarrow \pi^{*}{ }_{\mathrm{C}-\mathrm{X}}$ delocalisation $(u-1$ $(56.75)<t u-1 \quad(73.52)<s u-1 \quad(83.60 \mathrm{kcal} / \mathrm{mol})$ at $\mathrm{MP} 2(\mathrm{fu}) / 6-31+\mathrm{G}^{*}$ level $)$. The stronger electron delocalisation in $s u-1$ may be attributed to larger polarisability of the $\mathrm{Se}=\mathrm{C}$ bond.

\section{Acknowledgements}

We thank the Department of Science and Technology (DST), New Delhi for financial assistance. 


\section{References}

1. (a) Whitham G H 1995 Organosulfur chemistry (New York: Oxford University) p. 85; (b) Weitzel F and Wendel A 1993 J. Biol. Chem. 268 6288; (c) Shamberger R J 1983 Biochemistry of selenium (New York: Plenum); (d) Reily C 1996 Selenium in food and health (London: Blackie)

2. (a) Fuchs O 1996 Chem. Listy 90 444; (b) Mont W W, Mugesh, Wismach C and Jones PG 2001 Angew. Chem. 40 2486; (c) Berry M J, Kieffer J D, Harney J W and Larsen P R 1991 J. Biol. Chem. 266 14155; (d) Berry M J, Banu L and Larsen P R 1991 Nature (London) 349438

3. (a) Flohe L, Gunzler W A and Schock H H 1973 FEBS Lett. 32 132; Raes M, Micheils C and Remacle 1987 J. Free Radical Biol. Med. 3 3; (c) Krebz-Remy C, Mehlen P, Mirault ME and Arrigo A P 1996 J. Cell Biol. 1331083

4. (a) Lambert C, Hilbert M, Christiaens L and Dereu N 1991 Synth. Commun. 21 85; (b) Ruwet A and Renson M 1969 Bull. Soc. Chim. Belg. 78 571; (c) Fong M and Schiesser C H1997J. Org. Chem. 62 3103; (d) Erdelmeier I, Tailhan-Lemont C and Jean-Claude Y 2000 J. Org. Chem. 658152

5. Ostrovidor S, Franck P, Joseph D, Martarello L, Kirsch G, Belleville F, Nabet P and Dousset B 2000 J. Med. Chem. 431762

6. (a) Murai T and Kato S 2000 Top. Curr. Chem. 208 177; (b) Beck T G 1999 Organoselenium chemistry: A practical approach (Oxford: University Press)

7. Koketsu M, Suzuki N and Ishihara H 1999, J. Org. Chem. 646473

8. Taurog A, Dorris M L, Hu W X and Guziec F S 1995 J. Biochem. Pharm. 49701

9. (a) Guzman J F B, Skrydstrup T, Lopez-Castro A, Millan J D and Estrada de Oye M D 1992 Carbohydr. Res. 237 303; (b) Dianez M J, Estrada M D and Lopez-Castro A 1993 Carbohydr. Res. 242 265; (c) Pathirana H M K K, Weiss T J, Reibenspies J H, Zingaro R A and Meyers E A 1994 Z. Kristallogr. 109 697; (d) Billing D J, Ferg E E, Lai L L, Levedis D C and Reid D H 1993 Acta Crystallogr. C49 917

10. Pazdera P, Sibor, Marek R, Kuty M and Marek J 1997 Molecules 2135

11. (a) Bharatam P V, Uppal P and Bassi P S 1997 Chem. Phys. Lett. 276 31; (b) Leszczynski J, Kwaitkowski J S and Leszczynska D 1992 J. Am. Chem. Soc. 11410089

12. Sakaizumi T, Yasukawa A, Miyamoto H, Ohashi O and Yamaguchi 1986 Bull.Chem. Soc.Jpn 591614

13. (a) Wiberg K B and Rush D J 2001 J. Am. Chem. Soc. 123 2038; (b) Wiberg K B and Rablen P R 1995 J. Am. Chem. Soc. 117 2201; (c) Wiberg K B and Breneman C M 1992 J.Am.Chem. Soc. 114 831; (d) Wiberg K B, Breneman C M and Lepage T J 1990 J. Am. Chem. Soc. 112 61; (e) Wiberg K B 2000 In The amide link (eds) A Greenberg, C M Breneman and J F Liebman (New York: Wiley) p. 41

14. Glendening E D and Hrabal J A II 1997 J. Am. Chem. Soc. 11912940

15. Laidig K E and Cameron L M 1996 J. Am. Chem. Soc. 1181737

16. Lauvergnat D and Hilberty P C 1997 J. Am. Chem. Soc. 1199478

17. (a) Hehre W J, Radom L, Schleyer P V R and Pople J A 1986 Ab initio molecular orbital theory (New York: Wiley-Interscience); (b) Foresman J B and Frisch E 1996 Exploring chemistry with electronic structure methods 2nd edn (Pittsburgh, PA: Gaussian Inc.)

18. (a) Parr R G and Yang W 1989 Density-functional theory of atoms and molecules (New York: Oxford University Press); (b) Bartolotti L J and Fluchick K 1996 In Reviews in computational chemistry (eds) K B Lipkowitz and D B Boyd (New York: VCH) vol. 7, pp 187-216

19. Frisch M et al 1995 Gaussian 94, Revision B.2 (Pittsburgh, PA: Gaussian, Inc.)

20. Krishnan R, Frisch M J and Pople J A 1980 Chem. Phys. Lett. 724244

21. (a) Becke A D 1993; J. Chem. Phys. 98 5648; (b) Lee C, Yang W and Parr R G 1980 Phys. Rev. B37 785; (c) Perdew J P and Wang Y 1992 Phys. Rev. B45 13244

22. Scott A P and Radom L 1996 J. Phys. Chem. 10016502

23. (a) Reed A E, Weinstock R B and Weinhold F 1985 J. Chem. Phys. 83 735; (b) Reed A E, Curtiss L A and Weinhold F 1988 Chem. Rev. 88899 